\title{
试论 BIM 技术在地铁施工过程周边建筑加固中的应用
}

\section{The Application of BIM Technology to the Reinforcement of the Construction of the Subway 魏耀金金}

Yaoxin Wei

中铁广州工程局集团深圳工程有限公司 中国·广东广州 510000

China Railway Guangzhou Engineering Bureau Group Shenzhen Engineering Co.,Ltd., Guangzhou, Guangdong, 510000, China
【摘要】论文主要以 BIM 技术在地铁施工过程周边建筑加固中的应用为重点进行阐述, 从 建筑物加固措施、加大现有建筑物的监控力度、创建建筑物加固的 BIM 模型几个方面进行研 究分析,其目的在于充分发挥 BIM 技术的积极作用,更好地保障地铁工程周边建筑安全性。

【Abstract】In this paper, the application of BIM technology in the reinforcement of surrounding buildings during subway construction is expounded, and the BIM model of building reinforcement is studied and analyzed from the aspects of building reinforcement measures, strengthening the monitoring of existing buildings, and establishing the BIM model of building reinforcement.

【关键词】施工技术; 地铁施工; 建筑加固

【Keywords】construction technology; subway construction; building reinforcement 【DOI】10.36012/etr.v1i4.709

\section{BIM 技术概述}

建筑信息模型，又称为 Building Information Modeling,简 称 “BIM 技术”，在施工控制及可视化模拟当中应用 BIM 技 术, 能够更好地实现可视化目标, 提高设计效果, 并且对模型 效果图进行严格的检验。与此同时，还能够录入时间信息内 容, 实现 4D 效果, 保障其能够具有良好的监控功能。将模拟 情况同现实世界进行对比，相关的项目管理人员能够更好地 规避项目当中存在的问题与漏洞，从而充分保障施工质量的 提升 ${ }^{[1]}$ 。在整个施工过程当中, 应用 BIM 技术, 还需要对其进 行三维碰撞检验、三维虚拟施工等。基于此, BIM 技术的应用, 能够有效减少人力、物力的投入, 降低施工成本, 更好地对项 目控制进行优化, 实现资源利用最大化的目标。

\section{BIM 技术同建筑加固保护结合}

通常来讲, 地铁工程大都位于城市的中心位置, 而且同居 民楼及大型商场距离相对较近, 部分地铁甚至还位于建筑物 的下方位置。为了能够充分保证地铁施工更加具有安全性, 就
需要借助BIM 技术。若想将 BIM 技术更好地融入建筑物加固 技术当中, 就需要对地铁的施工进度进行详细分析, 然后借助 4D 形式, 对施工过程进行模拟, 并结合实际的施工情况, 对建 筑物保护效果进行相应的评估分析, 有效调整加固方法, 然后 再采用 PDCA 方法对质量计划进行循环的调整优化，从而制 定出最为合适的处理措施,使工程达到最优效果。

\section{1 建筑物加固措施}

\section{1 .1 应用注浆加固方法}

在对建筑物本身进行加固、提高建筑物稳定性的过程中, 最为常用的就是对地基进行注浆加固。而注浆的方法又可以 分为多种类型, 根据注浆压力可以分为静压注浆、高压注浆两 种形式。在中国地铁进行施工的各个过程当中, 注浆方法得到 了广泛的应用。

应用注浆施工的方法对建筑物地基进行加固(见图 1), 并且对周边的区域进行隔离, 不仅能够有效保护周边的建 筑物, 还能够提高建筑物的稳定性, 防止其发生沉降变形等 情况。 


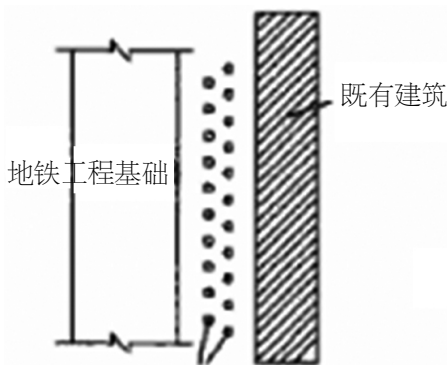

垂直及倾斜注浆孔

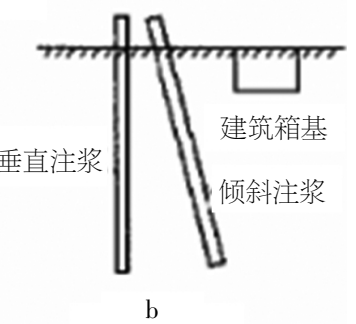

图 1 注浆加固保护

2.1 .2 应用隔离桩法

在开展地铁施工的过程中, 采用隔离桩法, 能够有效防止 周边建筑物地基出现变形的情况, 有利于对地基变形情况进 行合理的控制, 将其局限在隔离桩范围内, 实现有效加固建筑 物地基的目标, 最大程度防止地基变形情况向外延伸, 影响周 边建筑物的地基。在此过程中,应用隔离桩能够有效降低地铁 施工周边建筑物地基产生的影响,降低地基当中的水压力、土 壤密度影响变化等, 尽量降低对建筑物地基产生的影响。

\section{1 .3 应用地下连续墙法}

在开展地铁施工过程中, 施工单位开挖深基坑时, 通常会 采用连续墙隔断法。通过实施地下连续墙的方法, 能够有效解 决地基坑外边土体位移问题，更好地对周边建筑物地基变形 问题进行有效的控制。

\section{1 .4 其他应用方法}

另外,在开展地铁施工过程中, 还可以在原本的基础上增 加刚性桩, 承担原地基的负荷。最为常用的方法就是树根桩、 微型钻孔钢管桩等。

\section{2 加大现有建筑物的监控力度}

在开展地铁施工过程中, 要严格按照时间进度, 对其中的 各个关键部位的变化情况进行严格监督。与此同时, 在设置监 测点时, 应对基坑周边的位置、建筑物易发生沉降的位置等, 根据采用的不同加固保护措施，设置不同的检测控制点。另
外, 对于检测到的数据都要输人数据库当中, 对建筑物的变 形、位移等情况进行详细的分析, 为下一步施工工作的开展提 供有利条件。

\section{3 创建建筑物加固的 BIM 模型}

通过数据库管理软件的应用, 结合三维 $\mathrm{CAD}$ 显示软件, 对地铁工程及相关内容建立三维模型, 然后采用相关的软件, 协同地铁工程的施工进度、过程检测及加固措施, 将信息内容 融入其中, 为实现在地铁工程施工模拟进度管理更好地应用 BIM 技术提供有利条件。

第一,将当前建筑物的模型信息输入相关系统中,如建筑 物的外轮廓等, 为后续进行加固处理提供有利条件, 更好地对 相应位置进行判断。通俗来讲, 就是运用 BIM 图形判断中的 碰撞检测，最大程度上防止加固建筑物同原有建筑物在地下 空间发生碰撞。

第二,将现阶段地铁工程中的空间信息输入系统中,如隧 道、车站等,还可以将其他设计图中的信息导入系统, 然后应 用三维显示的方法对位置进行检查。

第三, 在模型中输入加固措施所需要的内容, 如隔离柱、 隔离墙等。

在此过程中,还需要将地铁施工现场周边的地下管线信息 输入模型中, 最大程度上防止加固工程对周边建筑造成影响。

\section{4 结语}

在开展地铁施工时, 应用 BIM 技术, 并结合建筑加固技 术,将建筑物发生沉降变形的数据信息输入相应软件,然后对 建筑物未来发生变形的趋势进行模拟分析，判断当前采取的 措施是否能够充分满足地基加固的基本需求，进而提出相应 的解决措施, 为实现高效施工目标奠定良好基础。

\section{参考文献}

[1]孙贤斌,刘倍. BIM 技术在地铁施工管理中的应用研究[J]]湖北 工业大学学报,2018,33(2):87-90. 